\title{
MAKING SENSE BEHIND THE LENS: Closed Circuit Television AND THE DUTCH Customs OfFice
}

\author{
KEES ARTS, STEFFIE VAN DEN BERG, ADINDA LODDERS, \\ PIETER WAGENAAR, DANIEL DE WIT*
}

\section{INTRODUCTION}

The use of Closed Circuit Television (CCTV) increased markedly during the last decades of the $20^{\text {th }}$ century. After initial experiments with it in the $1960 \mathrm{~s}$, it rapidly grew during the $1990 \mathrm{~s}^{1}$. Surveillance cameras have now become part of our daily lives, appearing with increasing frequency at such places as shopping malls, railway stations, city centres, highways, ports and airports. As these cameras are used at many different locations, the parties employing them vary as well. They can be public security services, but also private ones. With so many entities erecting cameras, it is no wonder that London was already using half a million in 2002, and that the total number for the entire UK stood at four million ${ }^{2}$. How high the numbers are at present is unknown, but further exponential growth seems plausible.

Surveillance cameras are a relatively recent phenomenon, but the ideology behind them is not. Already in the $18^{\text {th }}$ century the philosopher Jeremy Bentham theorized about (the illusion of) ever-present supervision bringing about self-discipline. These theories were put into practice in his design of

DOI: $10.2478 /$ wrlae-2014-0102

*VU University Amsterdam, The Netherlands.

${ }^{1}$ Benjamin J. Goold, CCTV and Policing: Public Arena Surveillance and Police Practices in Britain (Oxford University Press 2004); Leon Hempel and Eric Töpfer, 'CCTV in Europe: Final Report' (2004) The Urbaneye Working Papers Series no 15 , $\leq$ http://www.urbaneye.net/results/ue wp15.pdf $>$ accessed 23 November 2012;

Michael McCahill and Clive Norris, 'CCTV in Britain' (2002) The Urbaneye Working Papers Series no 3, $\leq$ http://www.urbaneye.net/results/ue wp3.pdf $>$ accessed 23 November 2012; Clive Norris and Gary Armstrong, The Maximum Surveillance Society. The Rise of $\overline{C C T V}$ (Berg 1999).

${ }^{2}$ Hempel,Töpfer (n 1); Clive Norris, Mike McCahill and David Wood, 'Editorial. The Growth of CCTV: a global perspective on the international diffusion of video surveillance in publicly accessible space' (2004) 2 (2/3) Surveillance \& Society 110; Michael McCahill and Clive Norris, 'CCTV in London' (2002) The Urbaneye Working Papers Series no 6, $\leq$ http://www.urbaneye.net/results/ue wp6.pdf $>$ accessed 23 November 2012;

Frank Helten and Bernd Fischer, 'Reactive Attention: Video Surveillance in Berlin Shopping Malls' (2004) 2 (2/3) Surveillance \& Society 323. 
the so-called 'panopticon': a domed prison with a central watch tower enabling the constant supervision of inmates. Running the chance of being observed at all times, Bentham believed, would slowly accustom the inmates to behaving as if they actually were always under inspection, and this would be a lasting effect. Inmates would thus gradually learn to mend their wicked ways. Two centuries later the French historian Foucault picked up where Bentham had left off. Yet, to him there was nothing desirable about panopticism. It was an example, and indeed a symbol, of the way governments have started to regulate our behaviour from the $17^{\text {th }}$ century onwards ${ }^{3}$.

Norris and Armstrong have explained that in reality CCTV does not produce panoptic outcomes ${ }^{4}$. However, alongside preventive purposes, CCTV is also used for repression: for detection and prosecution ${ }^{5}$. As CCTV can give proof of who was where, at what time, and what he was up to, these repressive purposes have often been the subject of debate. The cameras, after all, are pointed at all of us, not only at potential wrongdoers, and it is therefore also innocent citizens who get to be observed and whose movements are recorded.

Unsurprisingly, then, the rise of CCTV has been accompanied by increasing scholarly interest in its use ${ }^{6}$. Much attention has been devoted to the effect of CCTV on crime rates ${ }^{7}$. At the same time, what actually goes on behind the screens of the camera observers has started to attract attention too ${ }^{8}$. Most research in this second category has focused on CCTV use at shopping malls or in town centres. Far less attention has been paid to cameras at socalled 'heterotopias'.

'Heterotopias', yet another Foucauldian term, come in many forms, but they are always 'places set apart', places where nobody is at home. Such places are, in Salter's citation of Foucault, "in relation with all other sites, but in such a way to suspect, neutralize, or invert the set of relations that they happen to designate, mirror, or reflect" (Foucault 1986: 24) ${ }^{9}$. To camera observers this poses difficulties. They are always on the lookout for abnormal

\footnotetext{
${ }^{3}$ Michel Foucault, Discipline and Punish: The Birth of the Prison (Pantheon 1977).

${ }^{4}$ Clive Norris, 'From personal to digital. CCTV, the panopticon and the technological mediation of suspicion and social control' in David Lyon (ed), Surveillance as Social Sorting. Privacy, Risk and Digital Discrimination (Routledge 2003); Norris, Armstrong, The Maximum Surveillance Society (n 1).

${ }^{5}$ Anthony Giddens, The Nation State and Violence. Volume Two of A Contemporary Critique of Historical Materialism (Polity Press 1985); Hempel, Töpfer (n 1); Michael McCahill and Clive Norris, 'Literature Review' (2002) The Urbaneye Working Papers Series no 2, $\leq$ http://www.urbaneye.net/results/ue wp2.pdf $>$ accessed 23 November 2012.

${ }^{6}$ David Lyon, Surveillance Studies: An Overview (Polity Press 2007).

${ }^{7}$ Rachel Armitage, Graham Smyth and Ken Pease, 'Burnley CCTV Evaluation' (1999) 10 Crime Prevention Studies 225; Jason Ditton and Emma Short, 'Yes, it works, No, it doesn't: Comparing the effects of open-street CCTV in two adjacent Scottish Town Centres' (1999) 10 Crime Prevention Studies 201; Nick Tilley, 'Understanding Car Parks, Crime and CCTV: Evaluation Lessons from Safer Cities' (1993) Crime Prevention Unit Series Paper no 42, $<$ http://www.popcenter.org/problems/parking garage theft/pdfs/tilley.pdf $>$ accessed 23 November 2012.

${ }^{8}$ Norris, Armstrong, The Maximum Surveillance Society (n 1); Michael McCahill, The Surveillance Web: The Rise of Visual Surveillance in an English City (Willan Press 2001); Goold (n 1).

${ }^{9}$ Mark B. Salter, 'Governmentalities of an Airport: Heterotopia and Confession' (2007) 1 International Political Sociology 49
} 
behaviour, but as no one is at home in a heterotopia, 'normal behaviour' hardly exists there, and it is unclear what the observers should be looking for $^{10}$. At a shopping mall - not a heterotopia - the situation is much clearer. Running, for instance, is perceived as aberrant behaviour by camera observers, as it might signify shoplifters trying to get away. However, at an airport - according to Salter a prime example of a heterotopia ${ }^{11}$ - running occurs quite frequently, as passengers might be in a hurry to catch their connection. The same goes for loitering, or being disoriented or nervous: behaviour that would probably immediately catch the cameras' attention if occurred elsewhere ${ }^{12}$. The heuristics camera observers use at shopping malls, therefore, cannot be easily applied at airports. What heuristics camera observers do use at airports is relatively unknown, as the literature pertaining to the matter is still scarce ${ }^{13}$.

The primary purpose of this article is to fill in this gap in our knowledge of CCTV use. By performing an ethnographical case study on camera use at the customs office at Schiphol Airport (Amsterdam), we have tried to answer the following question: how do customs officers at Schiphol airport use CCTV, and why do they label certain events as suspicious? At the same time, we also try to fill in a second, and more important, gap: how do camera observers actually arrive at the heuristics they use? This second issue in particular is a victim of research neglect.

\section{THEORETICAL FRAMEWORK}

\section{CCTV operators' practices}

CCTV operators potentially watch everybody present in the area their cameras are pointed at. As they possess relatively little data on each individual in view of the cameras, in principle everybody is a suspect ${ }^{14}$. How do camera observers spot perpetrators in this vast mass of passers-by? The only way is by applying social sorting practices, which they develop on their own ${ }^{15}$.

If we want to find out how customs officers use their cameras, we have no other option than to take our knowledge of practices concerning camera observers' use at shopping malls or city centres as our point of departure. Literature pertaining to CCTV use at airports is, after all, extremely rare. Norris and Armstrong's studies on camera use at such places ${ }^{16}$ are seminal in the field of CCTV-studies. ${ }^{17}$ They have spent a total of 592 hours observing

\footnotetext{
${ }^{10}$ Pieter Wagenaar, Kees Boersma, 'Zooming in on 'heterotopia': CCTV operator practices at Schiphol Airport' (2012) 17 (1) Information Polity 7.

${ }^{11}$ Salter (n 9).

12 Wagenaar, Boersma (n 10).

13 Peter Adey, 'Secured and Sorted Mobilities: Examples from the Airport' (2003) 1 (4)

Surveillance \& Society 500; Wagenaar, Boersma (n 10).

${ }^{14}$ Norris, Armstrong, The Maximum Surveillance Society (n 1).

15 Goold (n 1); Lyon (n 6); McCahill (n 8); McCahill, Norris (n 5); Clive Norris and Gary Armstrong, 'CCTV and the Social Structuring of Surveillance' (1999b) 10 Crime Prevention Studies 157; Wagenaar, Boersma (n 10), Etienne C. Wenger and William M. Snyder, 'Communities of Practice: The Organizational Frontier' (2000) 1 Harvard Business 139-146.

${ }^{16}$ Norris, Armstrong, The Maximum Surveillance Society (n 1); Norris, Armstrong, 'CCTV and the Social Structuring of Surveillance' (n 15).

${ }^{17}$ Wagenaar, Boersma (n 10).
} 
CCTV operators in three English cities ${ }^{18}$. During these observations they made detailed descriptions of 888 'targeted surveillances', by which they mean: "either one which lasted more than one minute on an individual or group of individuals, or where it was initiated from outside the system (by police or private security for example), regardless of whether a target was identified"19. When analyzing their data they found that these "targeted surveillances' could be subdivided in to seven categories, based on the CCTV operators' reasons for closer observation. Goold later slightly altered their categorization, and added an eighth category (routine). We quote him verbatim:

\section{Table 1. Reasons for targeted surveillance ${ }^{20}$}

\begin{tabular}{|c|c|}
\hline Category & Elucidation \\
\hline Behavioural & $\begin{array}{l}\text { "suspicion based on the behaviour or demeanour of the } \\
\text { individual, such as acting aggressively towards others, } \\
\text { appearing to be drunk in public, or running down a busy } \\
\text { high street" }\end{array}$ \\
\hline Categorical & $\begin{array}{l}\text { "suspicion based on personal characteristics such as age, } \\
\text { dress, gender or race" }\end{array}$ \\
\hline Locational & $\begin{array}{l}\text { "suspicion based on an individual's location. Examples } \\
\text { might include an individual walking through a car park at } \\
\text { night or standing close to a bank cash-point"" }\end{array}$ \\
\hline Personalised & $\begin{array}{l}\text { "suspicion based on the prior knowledge of the individual, } \\
\text { such as knowledge of previous criminal behavior or } \\
\text { association with other known or suspected offenders" }\end{array}$ \\
\hline Protectional & $\begin{array}{l}\text { "monitoring for the purpose of ensuring the safety of the } \\
\text { individual targeted. Examples might include following an } \\
\text { unaccompanied child or a woman walking alone through } \\
\text { a deserted town center at night" }\end{array}$ \\
\hline Routine & $\begin{array}{l}\text { "monitoring carried out as part of a set surveillance } \\
\text { routine, such as watching security personnel pick up } \\
\text { money from a high street bank on a weekly basis" }\end{array}$ \\
\hline Transmitted & $\begin{array}{l}\text { "suspicion based on information from a source outside the } \\
\text { CCTV scheme, or where the initial surveillance was } \\
\text { commenced because of an outside request" }\end{array}$ \\
\hline Voyeuristic & $\begin{array}{l}\text { "surveillance for the purpose of personal interest or } \\
\text { gratification, sexual or otherwise" }\end{array}$ \\
\hline
\end{tabular}

Recently, Wagenaar and Boersma have done research into CCTV use by the Dutch military police (KMar) at Schiphol Airport ${ }^{21}$. They used Goold's categorization as a starting point, although it had been developed for studying camera observation at shopping malls. Their research shows that Goold's categories apply to the highly volatile environment of an airport as well.

\footnotetext{
18 Norris, Armstrong, The Maximum Surveillance Society (n 1).

19 ibid.

${ }^{20}$ Goold (n 1) 143.

${ }^{21}$ Wagenaar, Boersma (n 10); Francisco R. Klauser, Jean Ruegg and Valerie November, 'Airport surveillance between public and private interests: CCTV at Geneva International Airport' in Mark B. Slater (ed), Politics at the Airport (University of Minnesota Press 2008).
} 
However, Wagenaar and Boersma introduce a few small alterations, the most important being that 'categorical', 'behavioural', 'locational' and 'personalized' suspicion can be grouped under one broad category of 'free surveillance' at an airport ${ }^{22}$. And, as was previously predicted ${ }^{23}$, it turns out that the digitalization of CCTV has produced a new category: 'retrospective surveillance', which involves playing back stored images ${ }^{24}$.

Camera observers' practices are not neutral. The way CCTV operators use their cameras is a result of subjective choices. Especially in Norris and Armstrong's research this subjectivity clearly comes to the fore ${ }^{25}$. However, relatively little attention has been paid to where these subjective motivations come from. We have an idea of how camera operators make sense of what they see, but we know very little about the process of 'sensemaking' they go through.

\section{Sensemaking}

Sensemaking is an interpretative process during which people construe a meaning about ongoing events ${ }^{26}$. Sensemaking helps in structuring the unknown because it is - often unconsciously - used as a tool for understanding events we have difficulty interpreting. Sensemaking is not a noun, but a verb ${ }^{27}$. It is synonymous with ongoing judgment and opinion making, and is a process that is different for every individual. From a sensemaking perspective, there is therefore no one single truth. Sensemaking, as Muhren et al. say, is a process aimed at answering the following questions: "What is happening out there? Why is it taking place? What does it mean?"28.

Karl Weick, the most renowned sensemaking scholar, argues that sensemaking consists of seven properties: "Sensemaking is understood as a process that is (1.) Grounded in identity construction (2.) Retrospective (3.) Enactive of sensible environments (4.) Social (5.) Ongoing (6.) Focused on and by extracted cues (7.) Driven by plausibility rather than accuracy" 29 . Below we take a closer look at these seven properties of sensemaking.

1. Grounded in identity construction: Sensemaking starts with the individual going through a continual process of sensemaking ${ }^{30}$. Thus, the interpretation of what is happening differs between individuals. Each individual experiences his own perception of a certain event. The individual

${ }^{22}$ Wagenaar, Boersma (n 10).

${ }^{23}$ Heidi Mork Lomell, Ann Rudinow Sætnan and Carsten Wiecek, 'Flexible Technology, Structured Practices: Surveillance operations in 14 Norwegian and Danish organizations' (2003) The Urbaneye Working Papers Series no 9, $<$ http://www.urbaneye.net/results/ue_wp9.pdf $>$ accessed 23 November 2012; Hempel, Töpfer (n 1).

${ }^{24}$ Wagenaar, Boersma (n 10).

${ }^{25}$ Norris, Armstrong, The Maximum Surveillance Society (n 1); Norris,Armstrong, 'CCTV and the Social Structuring of Surveillance' (n 15).

${ }^{26}$ Maria L. Nathan, 'How past becomes prologue: a sensemaking interpretation of the hindsight-foresight relationship given the circumstances of crisis' (2004) 36 (2) Futures 181.

27 Willem J. Muhren, Gerd van den Eede and Bartel van de Walle, 'Sensemaking as a Methodology for ISCRAM Research: Information Processing in an Ongoing Crisis' (Proceedings of the 5th International Conference on Information Systems for Crisis Response and Management (ISCRAM), Washington D.C., May 2008).

28 ibid.

${ }^{29}$ Karl E. Weick, Sensemaking in Organizations (Sage Publications 1995).

30 ibid. 
characteristics of each sensemaker therefore play a huge part in sensemaking $^{31}$, even if it is the collective activity of an entire organization ${ }^{32}$. 2. Retrospective: Sensemaking is based on a critical comparison with previous experiences in order to interpret current events ${ }^{33}$. During the ongoing process of sensemaking an implicit 'database' of analogous events comes into being, with which future events will be compared.

3. Enactive of sensible environments: The individual involved in a sensemaking process is not a neutral observer, as he himself usually takes part in the situations he is trying to interpret ${ }^{34}$. The sensemaker thus influences these situations to a degree, which is why sensemaking consists of an interplay between the sensemaker and his environment.

4. Social: Sensemaking is a social process in the sense that the individual interprets events through conversation, interaction and dialogue with others ${ }^{35}$. Views and positions are mutually compared and adjusted, and then positions are taken on the basis of social expectations. Sensemaking is therefore, among other things, a social learning process.

5. Ongoing: Sensemaking has no real beginning or end ${ }^{36}$. As Weick puts it, "people are always in the middle of things" 37 . The perception an individual has is adjusted on the basis of new insights. At the same time, the event that is being interpreted keeps unfolding as well, which is another reason why sensemaking is an ongoing process.

6. Focused on and by extracted cues: Sensemaking is based on the observation of particular properties, which are related to broader views ${ }^{38}$. Or, in Nathan's words, "We pay attention and extract a particular cue, then link it with some other idea that clarifies the meaning of the cue, which then alters the more general idea to which we linked the cue, and on and on." 39

7. Driven by plausibility rather than accuracy: During the process of sensemaking the individual does not focus on precise and complete analyses of the actual events, but rather on certain properties of these events that stand out because they are useful and common. ${ }^{40}$ This is why sensemaking allows us to quickly react to these events.

In this article we use Weick's seven properties of sensemaking to analyze how CCTV operators give meaning to the digital images appearing on their screens. What we need to bear in mind, though, is that when CCTV operators try to interpret what's going on in front of their cameras' lenses, they are faced with a certain limitation: they only receive visual clues to a given situation, as sound is not transmitted through a CCTV system.

\footnotetext{
31 ibid.

${ }^{32}$ Muhren, van den Eede, van de Walle (n 27); Nathan (n 26); Weick, Sensemaking in Organizations (n 29).

${ }^{33}$ Muhren, van den Eede, van de Walle (n 27); Nathan (n 26).

${ }^{34}$ Karl E. Weick, 'Enacted Sensemaking in Crisis Situations' (1988) 25 (4) Journal of Management Studies 305, idem, Sensemaking in Organizations (n 29).

${ }^{35}$ Muhren, van den Eede, van de Walle (n 27).

${ }^{36}$ Willem J. Muhren, Foundations of Sensemaking Support Systems for Humanitarian Crisis Response, CentER Dissertation Series (Ph.D. diss., Tilburg University 2011).

${ }^{37}$ Weick, Sensemaking in Organizations (n 29).

38 ibid.

${ }^{39}$ Nathan (n 26).

${ }^{40}$ Weick, Sensemaking in Organizations (n 29).
} 


\section{METHODOLOGY}

As said before, the central question of this article consists of two parts: (1) how do customs officers at Schiphol Airport use CCTV, and why do they label certain events as suspicious? and (2) how do camera observers actually arrive at the heuristics they apply?

The first part of our central question has been the object of previous research. Norris and Armstrong pioneered a whole line of CCTV studies which provides the theoretical starting point of our research ${ }^{41}$. It also provides a portion of our research methodology. Norris and Armstrong use observation as their primary research method, and have developed research tools to match, which have later been adjusted by others including Goold ${ }^{42}$. To ensure reliability, validity and comparability with previous research, we have adopted the checklists developed by Goold for performing observations ${ }^{43}$.

The second part of our central question is more of a challenge, as research into 'sensemaking' - the other theoretical framework we have used - has not yet been done in CCTV studies, and sensemaking has in general proven a very difficult concept to operationalize. Muhren was the first to actually succeed in making sensemaking measurable, but he only managed to do so for two of its properties ${ }^{44}$. Weick himself writes of the seven properties of sensemaking that "this listing is more like an observer's manual or a set of raw materials for disciplined imagination than it is a tacit set of propositions to be refined and tested" 45 . Given all this, we too have chosen not to make a 'hard' operationalization of sensemaking, but rather to use it as a tool to better understand the reasons behind the mode of operation of camera observers. During our observations we therefore simply used open interviews to find out which - if any - properties of sensemaking applied to those working the cameras.

Our research consisted of a total of 217 hours of observation at two regions of the customs office at Schiphol Airport: 'Passengers', also called 'Pax', and 'Cargo'. During these 217 hours we observed 260 instances of targeted surveillance, defined as zooming in on an individual and following him/her for at least 30 seconds, at Cargo, and 195 instances at Pax. These targeted surveillances will be analyzed in the following sections.

\section{SCHIPHOL AIRPORT'S CUSTOMS OFFICERS AND THEIR HEURISTICS}

The Dutch customs office has three main tasks: a) inspection of ingoing and outgoing goods; b) monitoring the correct application of European and national customs legislation; and c) levying and collecting taxes. These tasks are not only of a fiscal character, but also concern safety, health, the economy and the environment.

\footnotetext{
${ }^{41}$ Norris, Armstrong, The Maximum Surveillance Society (n 1).

${ }^{42}$ Norris, Armstrong, The Maximum Surveillance Society (n 1); Goold (n 1).

${ }^{43}$ Goold (n 1).

${ }^{44}$ Nathan (n 26)

${ }^{45}$ Weick, Sensemaking in Organizations (n 29).
} 
The customs office is divided into a national office and nine regions. Schiphol Airport houses two of these regions: 'Schiphol PAX and 'Schiphol Cargo'. Both regions have been using a CCTV system for a few years now, which they operate through the airport's joint control room system GMI. Schiphol Passengers inspects passengers and the goods they carry with them, levies taxes over these goods, and is involved in surveillance. Cargo's tasks are exclusively related to checking and regulating the flow of goods. Both regions use direct physical supervision along with CCTV in executing their tasks.

The two CCTV teams employed at Schiphol Airport - Pax and Cargo - have several tasks: they watch the CCTV system's monitors, they direct personnel at floor level on the basis of CCTV images, and they coordinate customs officers' reactions to incidents. Currently, the Pax team consists of twelve officers, one female and eleven males, who differ markedly in age. Cargo employs seventeen officers, with that cohort containing about as many males as females, who also differ in age. Both regions train their CCTV operators using the same pattern: standard training for customs officers (all operators have been previously employed in physical surveillance) combined with a short course on CCTV use.

The Cargo control room coordinates inspections for all airports in the Netherlands; CCTV operating is just one of the tasks for the officers working there, whereas the Pax control room is dedicated exclusively to CCTV use exclusively. Pax cameras often simply register passenger flows, but they are also operated by hand to target certain individuals. Cargo's observational method is more static. It just watches the flow of goods going in, out, and around airplanes. Both regions use fixed as well as moveable (dome) cameras. The moveable cameras can pan 180 degrees, and tilt 90 degrees. The fixed cameras cannot be moved.

Our observations of the way the cameras are used show that both of the regions start with performing risk analyses of flights. Then they routinely watch high risk flights. All observation could therefore simply be classed under Goold's 'routine' category, but his classification also allows for a subdivision within this category. In the table below the subdivision is shown for both regions, with the percentages of targeted surveillances we have observed given per category.

Table 2. Targeted surveillance at Pax and Cargo

\begin{tabular}{|l|l|l|}
\hline & Pax & Cargo \\
\hline Behavioural & $25.6 \%$ & $5.8 \%$ \\
\hline Categorical & $27.7 \%$ & $0.4 \%$ \\
\hline Locational & $2.6 \%$ & $10.8 \%$ \\
\hline Personalized & $3.1 \%$ & $0.8 \%$ \\
\hline Protectional & $29.7 \%$ & $0 \%$ \\
\hline Routine & $1.5 \%$ & $78.1 \%$ \\
\hline Transmitted & $7.7 \%$ & $0.4 \%$ \\
\hline Voyeuristic & $2.1 \%$ & $3.8 \%$ \\
\hline
\end{tabular}


At Pax, three categories of surveillance stand out: 'protectional', 'behavioural', and 'categorical'. It is important to note that 'categorical surveillance' here does not mean the kind of discrimination so markedly present in many other CCTV studies, but rather concerns social sorting on the basis of risk analysis that the customs office has performed by trying to think like a criminal organization. Quite often the camera observers combine categorical with behavioural surveillance, as they are looking for the 'total picture' of a criminal. It is therefore not only certain categories of people on certain flights that attract the cameras' attention: the camera's targets also have to behave in a certain manner to become objects of suspicion.

At Cargo, routine surveillance plays the most important role. The reason behind this is that the procedure for loading and unloading planes is always similar. Camera observers therefore do not have to select what they are looking for, but simply watch everybody in front of the camera. At the busiest moment there are about fifteen people working in and around an airplane, all of which become objects of targeted surveillance. Because the CCTV operators zoom in on the people under surveillance to establish on the basis of their uniforms to which organizations they belong, routine surveillance often coincides with categorical surveillance.

\section{SENSEMAKING: THE REASONS BEHIND THE HEURISTICS}

Pax

Why do customs camera operators label some situations, characteristics and behaviours suspicious? For Pax customs officers, sensemaking provides part of the answer. In the following section we analyze their practices using Weick's properties, while for reasons of composition we treat them in a different order than Weick does.

Processes of sensemaking at Pax are first of all social in character. CCTV operators make sense in interactions with their colleagues. It is during discussions with their peers that they corroborate their findings and the ensuing suspicions.

Identity construction explains part of the sensemaking process as well. The customs office exhibits a culture that assigns great importance to performance. Its success in intercepting narcotics or cash is very important to its officers. This contributes to their 'we-feeling', which is why success stories are repeated on multiple occasions. To CCTV operators at Pax, who feel they still have to prove themselves to their colleagues at physical surveillance, stories of their own personal success are just as important. They all have their own areas of interest and specializations. Some spot large amounts of cash by looking for expensive watches, others faultlessly spot a drug mule, and there is even a subdivision between specialists in finding drug mules who swallow latex balloons and those who spot drug mules who have inserted the balloons rectally. This achievement-oriented culture naturally influences the process of sensemaking.

The retrospective property of sensemaking also plays an important part in interpreting the images on the monitors. CCTV operators learn from past experiences with the way illegal goods are smuggled into the country and 
how smugglers behave at an airport. All camera observers have a background in physical surveillance, and this is how they know what behaviour to look for. They bring such experience with them when they become CCTV operators. Past experience has influenced the development of the CCTV system as well. An example of this is observing physical surveillance at specific locations (handling space, end desk). Experience has proven the usefulness of this, which is why these locations are fitted out with CCTV.

The customs officers' sensemaking is clearly focused on and by extracted cues. Important information extracted from past situations is used in the interpretation of new ones. This is how Pax operators have learned which behaviours and characteristics are typical of drug mules, like conspicuous gum chewing, looking around nervously, constant texting with mobile phones, travelling alone, or wearing winter clothes whilst having arrived from a tropical country. When CCTV operators spot one or more of these characteristics, they choose to do a targeted observation.

Sensemaking at Pax is also ongoing, which means that the interpretation of images has to be renewed continuously. As drug traffickers frequently adjust their modus operandi because the customs office has discovered how they work, the customs officers need to do the same. This also means that areas previously not covered by the Pax CCTV system now fall within the cameras' reach.

That plausibility is more important than accuracy in the Pax sensemaking process becomes clear from the fact that plausible explanations are sought when a passenger is behaving suspiciously. The conspicuous gum chewer is an example ('he's obviously trying to hide the smell of the latex balloons he has swallowed'), as is the passenger arriving from a tropical country but wearing a winter coat ('he's obviously hiding something in the coat's lining'), and the expensive wrist watch ('probably a fake' or 'don't we have something to declare, sir?'). Plausibility is, of course, closely related to cue extraction, as it is previous experience that determines the plausibility of an explanation.

The last property of sensemaking is enactment. It sometimes happens that CCTV operators influence situations. In such cases they are in contact with physical surveillance, where they relay what they see and what meaning they assign to these images. Sometimes physical surveillance acts on this information, and then it becomes clear whether the CCTV operator has attached the right meaning to the images. This, however, does not happen often, as the mode of cooperation between CCTV and physical surveillance has not yet been optimized.

In summary, therefore, it can be said that the sensemaking of CCTVoperators at Pax is to a very high degree a conscious process. The social context, the customs office's identity and that of the individual officers, experiences from the past and involvement in physical surveillance's actions all contribute to this. However, because 'enactment' is rare, involvement in the actions of physical surveillance does not occur very frequently at present. Would enactment become a more conscious process, the effectiveness of camera surveillance could be further improved, which is something the Pax CCTV operators appear to have a profound wish for. 


\section{Cargo: the evident sensemaking properties}

As we have seen at Pax, CCTV operators have a 'framework' for what to look for. This framework has developed over time, through all of Weick's sensemaking properties. Before we can try to determine whether Cargo also has such a framework, we need to note that, contrary to Pax, Cargo uses a static form of surveillance. It usually looks at one high-risk flight at a time, which explains the high percentage of routine surveillance at Cargo that we have seen in the previous section. As there is only a very limited number of people visible on the monitors most of the time, it is not possible to find clues for suspicious behaviour from behind the screens. This is the reason why CCTV operators at Cargo have ample opportunity to use the cameras on their own initiative. They constantly zoom in on seemingly trustworthy individuals in completely normal situations, a form of camera use that appears to be devoid of sense, but is actually quite sensible. By focusing on the activities of a limited number of Schiphol employees, the Cargo CCTV observers hope to find the needle in the haystack.

If we look at Cargo's camera use through Weick's sensemaking lens, we find that the social context property is part of the explanation for this operational mode: CCTV operators influence one another in an informal manner. However, although they constantly tell each other stories, there is no way to check whether camera observers actually act on these 'lessons learned'.

Identity construction is another sensemaking property that explains Cargo's camera use. CCTV operators enjoy broad discretion in how to use their cameras, which means they all develop their own areas of interest, specializations and deviations from formal protocols. Whether these specialized ways of observing actually help in delivering the goods is unknown, as Cargo has never succeeded in catching a perpetrator red-handed.

Example 1. Cargo is looking at the 10:30 AM airplane from Johannesburg.

Everything looks normal. The cargo has been unloaded, and a team of cleaners has gone aboard. Then the 'toilet cart' arrives, and parks at the rear of the plane. There is nothing suspicious about this situation. Because there is hardly anything else to see on the monitor, the observer zooms in for a while (ongoing). Because of his experience in physical surveillance, the observer knows where the hiding places in an airplane are (retrospective). After about 45 minutes, the driver of the toilet cart disconnects his pump and leaves for the next airplane. Nothing suspicious could be found in the driver's behavior (focused on and by extracted cues).

The retrospective property of sensemaking is very visible in a statement one of the operators made to us: "One needs to have worked on the platform to know how to use the camera. The cleaners can take anything out of the planes and hide it between these big vacuum cleaners and garbage bags 
of theirs." Operators thus use past experience to understand the present, and it is past experience that they have in spades. Just like Cargo's operators, the Pax camera observers all have a background in physical surveillance. Past experience has taught them the way people should behave, and when zooming in on the limited number of workers around an airplane this is what keeps them focused for a longer time. They are trying to find deviations from what they know to be the normal picture.

This operational mode - trying to find suspicious things in perfectly normal-looking situations in the absence of clues beforehand that something is actually wrong - shows how sensemaking is focused on and by extracted cues as well. When a vehicle is parked in an unusual spot, or when a worker on the platform is wearing unusual clothes, operators have an immediate cue that something might be wrong.

The fifth property of sensemaking, ongoing change, can also be observed at cargo. As with Pax, Cargo's CCTV operators are aware that smuggling routes change constantly, and that smugglers' behavioural patterns can change just as quickly. Making sense of images is therefore in constant flux and interpretation is always in need of renewal.

\section{Cargo: non-existent sensemaking properties}

It is (the lack of) the last two properties of sensemaking that explains Cargo's limited success in catching smugglers with their pants down: (1) driven by plausibility rather than accuracy and (2) enactive of sensible environments. CCTV operators at Cargo try to be accurate when using their cameras instead of looking for plausible cues. They simply observe everything. This has little to do with the officers operating the cameras, but is rather the result of what can be seen on the screens. As there is very little activity around the planes that have been unloaded, operators are in a position to focus on everything. Because there is never any suspicious behaviour to be seen on the monitors, the sensemaking property enactive of sensible environments does not materialize either. As nothing fishy can be seen behind the screens, physical surveillance's rapid-response team does not often act, and there is therefore no feedback on how Cargo's operators use their cameras. The example below is a very rare example of a physical response we found during our research.

To summarize our findings: because Cargo's CCTV operators look at all activities during the unloading of an airplane, they can only observe a very limited number of planes. This is the reason why two of Weick's sensemaking properties have not developed sufficiently, which has had negative consequences for the entire sensemaking process. 
Example 2. Whilst observing a high risk flight from Mexico the observer appears to be randomly using his cameras, until the moment the cleaning team's van arrives. While the cleaners board the plane the observer phones the rapid-response team. The observer thinks he might have recognized one of the cleaners from 'a weird incident a while ago'. During this incident itself no suspicious behavior can be seen, but the operator calls for assistance nonetheless. The quick response team waits at a distance for the observer to give the signal. After 45 minutes, the cleaners leave the plane - hands full of garbage bags - and get in their van, which is then stopped by the customs officers. They search the entire van, and report that they've found nothing. The operator replies "Thank you, and what a pity. Well, we'll catch them another time".

\section{CONCLUSION AND Discussion}

Marked differences can be discerned between Pax and Cargo as concerns the answer to our first question "How do customs officers at Schiphol airport use CCTV and why do they label certain events as suspicious?" Although both customs office regions do their work primarily by applying routines and patterns, Pax employs heuristics to select suspicious passengers. Cargo, on the other hand, looks at everything and everybody in sight. Clear heuristics have not yet emerged. The explanation for this difference can be found by looking at the two regions' sensemaking processes.

Our case study shows that sensemaking explains both Cargo's limited success in using CCTV as well as the success of Pax in doing so. As the sensemaking properties driven by plausibility rather than accuracy and enactive of sensible environments hardly exist at Cargo, its sensemaking is incomplete. At Pax, on the other hand, where a complete set of sensemaking properties is in place, drug mules and other smugglers are spotted daily through digital images. Use of the concept of sensemaking thus not only highlights both customs office regions' impressive efforts in trying to interpret a constantly changing environment, but also shows why one of the regions is more successful in doing so than the other.

As far as we know, no 'Weickian' research has ever been done into the way CCTV operators 'make sense' of what they see, which we feel is a pity. One of the outcomes of our article, we hope, has been a demonstration of the usefulness of sensemaking in explaining why camera observers label some events as potentially suspicious. Of course, our research is not without limitations. We have studied but two cases, both within the framework of but one organization, at just one airport. Therefore, the representativeness and generalizability of our research is limited. Nevertheless, we feel we have 
shown the adequacy of sensemaking as a tool for explaining the differences in effectiveness between both camera observation rooms at the customs office. We find that it can indeed be used as an addition to Norris' and Goold's models and methodology ${ }^{46}$. It is a useful tool for finding the explanations for the phenomena these scholars describe, and a tool that might be of use to other CCTV researchers as well.

${ }^{46}$ Norris, Armstrong, The Maximum Surveillance Society (n 1); Goold (n 1). 